\title{
Relationship between production characteristics and breeding potential of 25-month old extensively managed Bonsmara bulls
}

\author{
S.M. Scheepers ${ }^{1}$, C.H. Annandale ${ }^{2}$ and E.C. Webb ${ }^{1 \#}$ \\ ${ }^{1}$ Department of Animal and Wildlife sciences, University of Pretoria, Pretoria 0002, South Africa \\ 2 Department of Production Animal Studies, University of Pretoria, Pretoria 0002, South Africa
}

\begin{abstract}
The aim of the study was to determine if the breeding potential of 25-month old Bonsmara beef bulls could be predicted from production characteristics. Forty-one Bonsmara bulls were included in an on-farm performance test (also known as the Phase D growth test) for a period of 180 days. At an average age of 24.7 months the bulls were subjected to a libido test and overall breeding soundness evaluation (OBE). The bulls were categorised into independent breeding potential categories according to the scores they obtained for the measured reproductive traits. The categories included sperm morphology and motility. One-way ANOVA revealed that none of the production traits measured had a significant effect on the different breeding potential categories. A positive correlation $(\mathrm{r}=0.33)$ was recorded between pre-weaning growth rate and percentage morphologically normal sperm, while a negative correlation $(\mathrm{r}=-0.36)$ was recorded between total acrosomal- and flagellar sperm defects and pre-weaning growth. A positive correlation was demonstrated between sperm motility and pre-weaning growth $(\mathrm{r}=0.36)$, and a consequent negative correlation $(\mathrm{r}=-0.38)$ between the percentage aberrant sperm movement and pre-weaning growth. The correlation between the percentage morphologically normal sperm and percentage progressively moving sperm was $r=0.50$, while the correlation between percentage morphologically normal sperm and aberrant and immotile sperm was $\mathrm{r}=0.48$ for both variables. The number of total defects correlated highly significantly with flagellar and acrosomal defects $(r=0.72$ and $r=0.93$, respectively) and correlated poorly with the total number of nuclear defects $(r=0.32)$. These results suggest that total sperm defects were mainly due to acrosomal and flagellar defects, rather than nuclear defects and as the percentage morphologically normal sperm decreased, the motility also decreased. High growth rates before weaning may have a positive effect, while high growth rates after weaning may have a negative effect on the breeding potential of a bull. None of the measured reproductive and production traits had a significant effect on libido score and thus, cannot be used to predict the libido of young extensively maintained bulls.
\end{abstract}

Keywords: Bovine, breeding potential, libido, production parameters, semen quality, spermatozoa

${ }^{\#}$ Corresponding author. E-mail: Edward.webb@up.ac.za

\section{Introduction}

Reproductive performance is of fundamental importance in livestock production and the related economics. Under extensive farming situations natural breeding is used most frequently. Therefore, effective reproducing ability of both bulls and cows in the herd is of economic importance (Crichton et al., 1987; Burrow \& Prayaga, 2004). Breeding potential generally refers to the reproductive capacity of a bull as influenced by whether or not the bull has reached puberty, the bull's sperm quantity and quality (morphology and motility), scrotal circumference (SC), breeding experience (Landaeta-Hernandez et al., 2001), libido, mating ability (absence of physical and pathological tribulations) and the social interaction with other animals in their breeding environment (Chenoweth et al., 1984).

Yearling beef bulls are an important component of natural mating schemes and the principal method employed to assess the reproductive potential of the bulls, and thus selection of the bulls, is by overall breeding soundness examinations (OBE) (Ellis et al., 2005). An OBE is a quick, reliable and cost- effective method of screening and classifying bulls in terms of breeding potential and thereby minimizing the use of sub-fertile bulls. To avoid the selection of bulls that are unable or reluctant to serve a cow, a bull should also be tested for serving ability prior to the commencement of the breeding season (Hoflack et al., 2006,). Physical examination of the genitalia of a bull is often used to assess breeding potential and it involves 
palpation of the penis, prepuce, the accessory sex glands, the scrotum and testes, measurement of SC and sperm evaluations (Parkinson, 2004). Bulls that service the largest number of oestrous synchronized heifers can be identified by using the mean libido score (Farin et al., 1989; Quirino et al., 2004). Using bulls with higher libido scores are reported to be beneficial in terms of pregnancy rates, time of conception, length of calving season and homogeny of calves at weaning (Blockey, 1981 a; Quirino et al., 2004).

Before a bull is selected as a sire in a herd, the performance (phenotype) of the animal has to be evaluated (Bourdon, 2000). A phase D performance test is used to evaluate the bull's performance under natural grazing conditions and is based on traits which are of particular importance to a cow/calf producer. Weaning weight is an important production trait as it reflects the milk producing ability of the dam and is also a measure of the calf's genetic potential for early growth. Average daily gain (ADG) is defined as the daily post-weaning weight increase, measured in g/day. The Kleiber ratio again is defined as the metabolic growth efficiency $\left(\mathrm{W}^{0.75}\right)$. Shoulder height $(\mathrm{mm})$ and body length $(\mathrm{mm}$, measured from shoulder to pin bone) are used as indicators of cost effective finishing of animals in feedlot situations. Scrotal circumference (SC) is one of the most important measures of reproductive ability in bulls as it correlates with the number and quality of sperm produced. Scrotal circumference is also positively associated with age at puberty of related females and because of its high heritability it can be employed as a tool to improve the herd's reproductive performance (Chenoweth, 1999).

It is believed that it is advantageous to make a decision on breeding animals based on economically important traits since selecting for these traits can lead to improved production of the herd. Yearling beef bulls are typically selected as potential herd sires on their performance in a growth performance test. Data are lacking on the relationship between performance test results and reproductive parameters, but previous results suggested that an unfavourable relationship exists (Ologun et al., 1981; Ellis et al., 2005).

The aim of the present study was to determine if the breeding potential of 25-month old, sexually inexperienced Bonsmara beef bulls can be predicted from production data.

\section{Materials and Methods}

The trial was conducted on sexually inexperienced Bonsmara bulls residing in the eastern Free State, South Africa. The exact coordinates of the farm are 29 $54^{\prime} 54.51^{\prime \prime} \mathrm{S}, 26^{\circ} 31^{\prime} 33.11^{\prime \prime} \mathrm{E}$ at an elevation of $1635 \mathrm{~m}$ above sea level. This area receives the majority of its annual rainfall from mid-October to March and the average annual rainfall varies from 720 to $750 \mathrm{~mm}$ /year. Themeda triandra and Heteropogon contortus are the dominant grass species. The trial was performed during the summer months, the average day-time minimum and maximum temperatures being 5 and $23{ }^{\circ} \mathrm{C}$, respectively. During the trial period the bulls were grazed on a mixture of the above-mentioned natural occurring grass pastures ad libitum and were fed on average $3.5 \mathrm{~kg} / \mathrm{head} /$ day of bull meal containing $130 \mathrm{~g}$ crude protein $/ \mathrm{kg}$.

The bull calves were born on the farm in 2004 and were reared together from birth onwards. They were all included in an on-farm performance test, also known as a Phase D growth test, for 180 days. This test took place from mid October to mid April 2005 and involved the evaluation of post-weaning growth under controlled conditions. The bulls were weighed twice weekly and body measurements, including measurement of scrotal circumference (SC), were recorded. After the performance test, the bulls were divided into four separate homogenous groups according to body weight.

The ages of the bulls ranged from 23 to 26 months (mean $24.7 \pm 0.70$ months) at the onset of the trial (Table 1). They were weighed prior to the onset of the trial (week 1), and weights ranged from 367.0 to $522.0 \mathrm{~kg}$ (mean $399.5 \pm 27.4 \mathrm{~kg}$ ). The bulls were allocated a number from 1 to 41 from the heaviest to the lightest bull. The bulls were also evaluated for structural soundness and any bull that displayed structural faults was excluded from the trial. Specific emphasis was placed on SC. Any bulls that had a SC $<330 \mathrm{~mm}$ were also excluded from the trial, as this is the minimum SC required for bulls weighing $400-500 \mathrm{~kg}$ to pass a breeding soundness evaluation (Parkinson, 2004).

During the second week a group of 30, non-pregnant intact, nulliparous Bonsmara heifers, also born during 2004, was selected to be used for the libido tests. All heifers were of similar weight to ensure that a homogenous sexual stimulant was used on all of the bulls during the libido tests. Eighteen of the selected heifers were treated with Crestar ${ }^{\circledR}$ (Intervet SA Ltd, Isando, RSA) to induce the onset of oestrus. During week 4, 12 days after the Crestar ${ }^{\circledR}$ treatment, the 18 heifers were placed in a grazing camp along with the 
Table 1 The mean ( \pm s.d.) for age, birth weight, body weight, 205 day growth index (205 GI), average daily gain (ADG), Kleiber ratio, shoulder height, body length, height: length ratio, skin thickness, scrotal circumference at end of performance test (SC Ts) and scrotal circumference at the end of the trial (SC Te) for the bulls used in the experiment

\begin{tabular}{lrrrr}
\hline Variable & $\mathrm{N}$ & Mean \pm s.d. & Minimum & Maximum \\
\hline Age (months) & 41 & $24.7 \pm 0.7$ & 23.1 & 26.1 \\
Birth weight (kg) & 41 & $34.9 \pm 3.9$ & 26.0 & 44.0 \\
Body weight (kg) & 39 & $399.5 \pm 27.4$ & 367.0 & 522.0 \\
205 GI (kg/day) & 35 & $103.5 \pm 7.4$ & 90.0 & 119.0 \\
ADG (g/day) & 35 & $105.5 \pm 12.3$ & 90.0 & 131.0 \\
Kleiber ratio & 35 & $104.6 \pm 10.8$ & 90.0 & 130.0 \\
Shoulder height (mm) & 41 & $1170.32 \pm 29.1$ & 1100.0 & 1233.0 \\
Body length (mm) & 41 & $1376.5 \pm 34.7$ & 1290.0 & 1433.0 \\
Height : length & 41 & $1.2 \pm 0.0$ & 1.1 & 1.2 \\
Skin thickness (mm) & 41 & $14.1 \pm 1.7$ & 11.0 & 18.0 \\
SCTs (mm) & 41 & $347.1 \pm 18.9$ & 316.0 & 387.0 \\
SCTe (mm) & 41 & $370.0 \pm 25.9$ & 330.0 & 420.0 \\
\hline
\end{tabular}

bulls, for a pre-test session of $24 \mathrm{~h}$, as described by Boyd \& Corah (1988). The pre-test session provided the bulls with some sexual stimulation as well as acclimatized them to the test conditions. Six heifers were assigned to each of the three groups of bulls used during the trial with a $3: 1$ male to female ratio.

The remaining 12 heifers were randomly allocated to six groups in pairs. Twelve days before the onset of the first libido test the six groups of heifers where treated with Crestar ${ }^{\circledR}$ one day apart. This resulted in two heifers showing oestrus on each of the six consecutive days of week 5 during which the libido tests were carried out.

Forty-one bulls were randomly divided into the six groups (A to F) with seven bulls in groups A to E each and six bulls in group F. The groups were assigned to successive weekdays from Monday to Saturday. Throughout week 5 these bulls were subjected to the libido test as described by Chenoweth (1986) with certain modifications. The tests were carried out in the morning to compensate for the possible effect that light intensity, heat and time of day may have on the expression of libido. For sexual stimulation before each test, as recommended by Boyd \& Corah (1988), each bull was allowed to observe the mating activity of another bull for a period of 10 minutes, before being tested. This was accomplished by placing the bulls into a pen adjacent to the test pen. The first bull tested on each day was prestimulated by watching a teaser bull mounting the heifers for a period of 10 minutes. The teaser bull was of the same age and weight as the rest of the experimental bulls and had no previous sexual experience, except for the pre-test session. Previous studies by Godfrey \& Lunstra (1989) and Blockey (1981b) reported that the sexual activity of bulls was enhanced by the presence and sexual activity of other males

For the test each bull was individually placed in a $20 \mathrm{~m} \times 20 \mathrm{~m}$ pen with a ground floor, containing two non-restrained oestrus heifers (Bailey et al., 2005). During a 10 minute period, a modified numerical system was used to record the sexual behaviour of each bull and transform it into a score for overall libido performance. The numerical system was as follows:

$0 . \quad$ Bull showing no sexual interest;

1. Sexual interest shown, only once

2. $\quad$ Positive sexual interest in female on more than 1 occasion;

3. $\quad$ Active pursuit of female with persistent sexual interest;

4. Bull has an erection/pre-ejaculation due to sexual excitement;

5. One mount or mounting attempt, with no service;

6. More than one mount or mounting attempts with no service;

7. One service followed by no further sexual interest;

8. One service followed by sexual interest, including:

a. Sniffing/licking at perineal region and showing Flehmen stance; 
b. Bull has an erection/pre-ejaculation;

c. Mounting attempts with no service;

9. Two services followed by no further sexual interest;

10. Two services followed by further sexual interest, including:

a. Sniffing/licking at perineal region and showing Flehmen stance;

b. Bull has an erection/pre-ejaculation;

c. Mounting attempts with no service.

Interest was defined as any form of sexual interest, including sniffing or licking at the perineal region and Flehmen stance. A Flehmen response was defined as the flexing of the bulls' nostrils and retraction of the upper lip followed by investigation of the female's perineal region. A mount or mounting attempt was defined as both front feet lifting from the ground, culminating in physical contact with the female, penile seeking, or intromission without the ejaculatory thrust. A service was a properly orientated mount on the posterior part of the female, followed by intromission and a deep ejaculatory pelvic thrust. Reaction time (time taken by the bull to reach each of the scores) was measured with the aid of a stopwatch. Care was taken to handle the bulls quietly to avoid anxiety and stress.

The average libido score and time taken to reach each score is set out in Table 2. None of the bulls used during the experimental period obtained a score higher than $8 \mathrm{~b}$, being one service followed by sexual interest, including sniffing/licking at perineal region and showing a Flehmen stance and/or the bull having an erection/pre-ejaculation.

Table 2 Mean ( \pm s.d.) of the overall libido score and time (sec) to reach each of the scores, indicating libido

\begin{tabular}{llccc}
\hline Variable & $\mathrm{n}$ & Mean \pm s.d. $(\mathrm{sec})$ & Minimum $(\mathrm{sec})$ & Maximum $(\mathrm{sec})$ \\
\hline Overall libido score & 41 & $4.7 \pm 1.6$ & 1.0 & 9.0 \\
Time taken to reach 1* & 39 & $26.5 \pm 38.0$ & 4.4 & 174.7 \\
Time taken to reach 2 & 20 & $75.1 \pm 97.7$ & 12.9 & 341.7 \\
Time taken to reach 3 & 24 & $40.9 \pm 39.1$ & 12.5 & 206.9 \\
Time taken to reach 4 & 30 & $105.4 \pm 103.8$ & 17.4 & 378.8 \\
Time taken to reach 5 & 19 & $179.8 \pm 148.3$ & 20.0 & 594.6 \\
Time taken to reach 6 & 8 & $359.8 \pm 196.5$ & 76.2 & 408.7 \\
Time taken to reach 7 & 3 & $180.9 \pm 199.1$ & 40.1 & 443.6 \\
Time taken to reach 8a & 3 & $216.2 \pm 203.5$ & 51.4 & 434.3 \\
Time taken to reach 8b & 2 & $355.9 \pm 110.9$ & 277.5 &
\end{tabular}

*1 - $8 \mathrm{~b}$ refer to the libido score based on the linear system as explained in the text above.

During week 8 an overall breeding soundness evaluation (OBE) was performed on all bulls. An overall score was allocated to the bull, which was derived from individual values for SC, sperm motility and morphology. Final categorisation of bulls as exceptional, acceptable and unsatisfactory potential breeders were dependent on this score (Chenoweth et al., 1988).

Scrotal circumference was measured by a qualified veterinarian. The testes were forced down into the scrotum and a metal scrotal tape was placed around the largest diameter of the scrotum. The average SC of the bulls at the end of the performance test (start of trial) and at the end of the trial are presented in Table 1. The testes and scrotum were manually palpated to ensure normal consistency and symmetry. The epididymis was also palpated for any detectable abnormalities. The prostate, ampullae, seminal vesicles and internal inguinal rings were rectally palpated for any detectable abnormalities. With the use of electro-ejaculation, the prepuce and penis were examined and semen samples collected from all bulls upon erection and ejaculation. This was a harmless procedure and yielded sperm of acceptable quality to be used in evaluating sperm morphology and motility.

The sperm-rich fraction of the semen was collected into a conical test tube. A $4 \mathrm{~mm}$ drop of diluted semen was placed on a pre-warmed microscope slide, covered with a cover-slide, and evaluated for the 
percentage progressively motile sperm. The eosin-nigrosin staining method and microscopy at 1000x magnification were used to determine the percentage live sperm (Vilakazi \& Webb, 2004). Sperm morphology was determined by evaluating the number of normal versus abnormal sperm per 200 sperm in the eosin-nigrosin stained smear (1000x magnification) (Palmer et al., 2005). Sperm morphology was evaluated for the percentage of normal sperm, percentage major defects (e.g. knobbed acrosomes, pyriforms, abnormal loose heads, dag defects, degenerative heads, mid-piece reflexes) and the percentage of minor defects (e.g. normal loose heads, distal droplets, curled end-piece and loose acrosomes).

For the statistical analysis the bulls were categorised into independent breeding potential categories, according to the scores obtained for the measured reproductive traits. The categories included sperm morphology and motility. For the sperm morphology category, the 41 bulls were divided into two groups with a threshold measurement of (1) $\geq 70 \%$ morphological normal sperm, and (2) $<70 \%$ morphological normal sperm. For the sperm motility category, the 41 bulls were divided into two groups (independent of sperm morphology category) and these threshold measurements were: (1) $\geq 70 \%$ motile sperm, and (2) $<70 \%$ motile sperm.

Statistical analysis of the data was performed by using the general linear models (GLM) procedure of the Statistical Analyses System (SAS, 2004). One way analysis of variance (ANOVA) of the effect of breeding potential groups was performed by means of the GLM procedure and the least square means (LSM) option. Age was included as a continuous variable. All procedures were assessed at a significance level of 95\% ( $\mathrm{P} \leq 0.05)$ for the critical values. Chi-square tests (log linear analysis) of independence and trend analysis were performed on all categorical data, while a Kruskal-Wallis non-parametric test was used to analyse the variance. The point biserial correlation was used to measure the association among the continuous variables that showed significant effects and breeding potential categories (SAS, 2004).

\section{Results and Discussions}

One-way ANOVA results indicated the growth measurements of the bulls did not have a significant effect on the sperm morphology categories (Table 4). Although the bulls were of similar age, those bulls with $\geq 70 \%$ morphologically normal sperm tended to have a lower body weight after the performance test than bulls with $<70 \%$ morphologically normal sperm. Knights et al. (1984) reported that semen traits are lowly correlated phenotypically with growth traits $(r=-0.08$ to $r=0.08)$.

The correlation (Table 3) between the 205-day growth index and percentage morphologically normal sperm was $r=0.33(\mathrm{P}<0.1)$. The statistical results presented in Table 3 suggest that slightly higher 205-day growth indices were associated with a greater percentage of morphologically normal sperm. A negative correlation $(\mathrm{r}=-0.36 ; \mathrm{P}<0.05)$ was recorded between the total acrosomal- and flagellar defects and the 205-day growth index. A positive correlation was observed between body length and 205-day growth index $(\mathrm{r}=0.47 ; \mathrm{P}<0.05)$, indirectly indicating that the bulls with longer body lengths may have more morphologically normal sperm. This implies that high growth rates after weaning may have a negative effect on fertility. Bulls with $<70 \%$ morphologically normal sperm tended to have a higher ADG index, compared to bulls with $\geq 70 \%$ morphologically normal sperm.

Bulls with $\geq 70 \%$ morphologically normal sperm tended to have a smaller SC, measured after the performance test and at the beginning of the trial, than bulls with $<70 \%$ normal sperm. These results are in agreement with results found by Smith et al. (1981) that a statistically significant relationship between SC and number of sperm existed, but this did not apply to percentage normal sperm. Their data suggest that bulls with the highest SC had a lower percentage of normal sperm cells and those bulls with the lower SC had the most normal sperm. The finding that bulls with a greater scrotal circumference have less morphologically normal sperm is, however, in disagreement with the findings of Moser et al. (1996). Their results showed that bulls with a large SC tended to have more morphologically normal sperm than bulls with smaller scrotal circumferences. In that study the total abnormalities tended to be lower for bulls with smaller testicular circumferences. The relationship regarding scrotal infrared temperature patterns with the natural mating fertility in beef bulls was studied by Lunstra \& Coulter (1997). It was found that the testes in the scrotum must be maintained at a temperature of 2 to $5{ }^{\circ} \mathrm{C}$ below body temperature to maintain normal spermatogenesis and a negative relationship between testis size $(\mathrm{SC}: \mathrm{r}=-0.29$, testis volume: $\mathrm{r}=-0.34)$ and pregnancy rate was found to exist. This indicates that a larger testis may be associated with lower fertility, 
Table 3 Correlation coefficients between sperm characteristics and growth measurements of 25 -month old Bonsmara bulls

\begin{tabular}{|c|c|c|c|c|c|c|c|}
\hline & BL & $\% \mathrm{PM}$ & $\% \mathrm{AM}$ & $\% \mathrm{I}$ & $\mathrm{MN}$ & $\begin{array}{l}\text { Total } \\
\text { AFD }\end{array}$ & Total D \\
\hline 205 GI & $.47 * *$ & $.36^{* *}$ & $0.38^{* *}$ & $0.31^{*}$ & $.33^{*}$ & $0.36^{* *}$ & $0.33^{*}$ \\
\hline BL & & $.35^{* *}$ & $0.32 * *$ & $0.41 * *$ & .06 & 0.15 & 0.09 \\
\hline
\end{tabular}

205 GI - 205-day growth index/ pre-weaning growth rate; BL - Body length; \% PM - Percentage progressive movement; \% AM - Percentage aberrant movement; \% I - Percentage immotile;

$\% \mathrm{MN}$ - Percentage morphologically normal sperm; Total ND - Total nuclear defects;

Total AFD - Total acrosome and flagellar defects; Total D - Total defects (normal-, nuclear-, acrosomal- and flagellar defects); $* * * \mathrm{P}<0.001, * * \mathrm{P}<0.05, *$ Not significant.

even though it is well known that larger testes in bulls are associated with better semen quality and indicated that bulls that had larger scrotal sizes exhibited higher scrotal temperatures and may possibly have abnormal testicular thermoregulation (Lunstra et al., 1978).

Production and growth measurements had no significant effect on sperm motility categories (Table 4). Data are lacking concerning the relationship between performance test results and reproductive parameters, but an unfavourable relationship has been reported previously (Ologun et al., 1981). In the present study the category with low sperm motility had numerically greater values for ADG (108.8 \pm 14.9 vs. $102.3 \pm 8.5)$ and Kleiber ratio $(107.1 \pm 13.4$ vs. $102.3 \pm 7.3)$ than the category with high sperm motility. Although these differences were not significant, the correlations between the measured traits suggest that high growth rates may have a negative effect on the breeding potential of a bull. A positive correlation (Table 3) was observed between sperm motility and the 205-day growth index $(\mathrm{r}=0.36, \mathrm{P}<0.05)$, and a consequent negative correlation $(\mathrm{r}=-0.38, \mathrm{P}<0.05)$ between the percentage aberrant sperm movement and 205-day growth index. The 205-day growth index was numerically greater in the category with high sperm motility $(105.1 \pm 6.8)$, compared to the category with low sperm motility $(101.8 \pm 7.8)$. Higher sperm motility was associated with higher growth rates before the age at weaning.

Body length measurements also tended to be numerically greater in the category with high sperm motility $(1380.4 \pm 29.6)$ than in the category with low sperm motility $(1371.5 \pm 40.6)$. A positive correlation (Table 3) was recorded between sperm motility and body length $(\mathrm{r}=0.35 ; \mathrm{P}<0.05)$, and a negative correlation between 205-day growth index and percentage aberrant sperm movement, as well as with percentage immotile sperm $(\mathrm{r}=-0.32$ and $\mathrm{r}=-0.41$ respectively; $\mathrm{P}<0.05)$. Higher sperm motility was associated with longer body length. Bulls with $\geq 70 \%$ progressively moving sperm recorded smaller SC $(\mathrm{P}>0.1)$ as measured after the performance test and at the beginning of the trial than the bulls with $<70 \%$ progressively moving sperm.

Semen ejaculates may show as few as $5 \%$ abnormal sperm, while others may approach $100 \%$. Fertility is usually not affected until the level of abnormal sperm exceeds 20 to $25 \%$, depending on the type of breeding system employed. Most morphologically abnormal sperm do not show progressive motility and therefore as the percentage of morphologically abnormal sperm increases, so the progressive motility decreases (Bearden et al., 2004). Similar results have been found in the present study as indicated by the high positive correlation between percentage morphologically normal sperm and the percentage progressively motile sperm $(\mathrm{r}=0.50 ; \mathrm{P}<0.001)$ and that between aberrant sperm movement and immotile sperm (Table 6; $\mathrm{r}=0.83 ; \mathrm{P}<0.001)$.

Total sperm defects were influenced to a greater extent by acrosomal and flagellar defects than nuclear defects. The number of total defects was highly correlated $(\mathrm{P}<0.001)$ with the flagellar and acrosomal defects (Table 5; r $=0.72$ and $r=0.93$, respectively) and lowly correlated to the total number of nuclear defects $(\mathrm{r}=0.32 ; \mathrm{P}<0.05)$. The nuclear defects did not correlate significantly with the total acrosome and 
Table 4 Mean ( \pm s.d.) effects of breeding potential categories on the growth measurements of 25 -month old Bonsmara bulls

\begin{tabular}{|c|c|c|c|c|c|c|c|c|c|c|}
\hline $\begin{array}{l}\text { Sperm fertility } \\
\text { category }\end{array}$ & $\begin{array}{l}\text { Age } \\
\text { (days) } \\
\pm \text { s.d. } \\
\end{array}$ & $\begin{array}{l}\text { BW (kg) } \\
\pm \text { s.d. }\end{array}$ & 205GI \pm s.d. & $\begin{array}{l}\text { ADG } \\
\text { (g/day) } \\
\pm \text { s.d. }\end{array}$ & $\mathrm{KR} \pm$ s.d. & $\begin{array}{l}\text { SH }(\mathrm{mm}) \\
\pm \text { s.d. }\end{array}$ & $\begin{array}{l}\text { BL }(\mathrm{mm}) \\
\pm \text { s.d. }\end{array}$ & $\begin{array}{l}\text { ST (mm) } \\
\pm \text { s.d. }\end{array}$ & SCTs \pm s.d. & $\mathrm{SCTe} \pm$ s.d. \\
\hline Morph $\geq 70 \%$ & $24.6 \pm 0.5$ & $391.4 \pm 9.5$ & $104.7 \pm 9.8$ & $103.2 \pm 8.4$ & $104.6 \pm 5.7$ & $1161.9 \pm 33.8$ & $1372.4 \pm 29.7$ & $14.1 \pm 2.0$ & $341.3 \pm 20.1$ & $367.3 \pm 24.5$ \\
\hline Morph $<70 \%$ & $24.7 \pm 0.8$ & $402.7 \pm 31.4$ & $103.0 \pm 6.4$ & $106.4 \pm 13.6$ & $104.6 \pm 12.4$ & $1173.4 \pm 27.2$ & $1378.0 \pm 36.7$ & $14.1 \pm 1.6$ & $349.0 \pm 18.4$ & $371.0 \pm 26.7$ \\
\hline Motil $\geq 70 \%$ & $24.7 \pm 0.7$ & $398.9 \pm 19.3$ & $105.1 \pm 6.8$ & $102.3 \pm 8.5$ & $102.3 \pm 7.3$ & $1170.4 \pm 27.9$ & $1380.4 \pm 29.6$ & $14.4 \pm 1.9$ & $344.0 \pm 17.3$ & $366.1 \pm 23.3$ \\
\hline Motil $<70 \%$ & $24.6 \pm 0.7$ & $400.4 \pm 36.8$ & $101.8 \pm 7.8$ & $108.8 \pm 14.9$ & $107.1 \pm 13.4$ & $1170.2 \pm 31.4$ & $1371.5 \pm 40.6$ & $13.7 \pm 1.3$ & $350.9 \pm 20.6$ & $375.0 \pm 28.8$ \\
\hline
\end{tabular}

BW - Body weights at time of test (kg); 205 GI - 205 day growth index/ pre-weaning growth rate; ADG - Average daily gain (g/day); KR - Kleiber ratio;

SH - Shoulder height (mm); BL - Body length (mm); ST - Skin thickness (mm); SCTs - Scrotal circumference at beginning of trial (mm);

$\mathrm{SCTe}$ - Scrotal circumference at end of trial (mm); Morph - Sperm morphology categories (\%); Motil - Sperm Motility category (\%).

Table 5 Correlation coefficients between morphological defects of sperm and percentage progressive sperm movement for 25-month old Bonsmara bulls

\begin{tabular}{llllll}
\hline & $\%$ PM & Total ND & Total FD & Total AFD & Total D \\
\hline \%PM & 1 & -0.06 & $-0.35^{*}$ & $-0.53 * * *$ & $-0.52^{* * *}$ \\
Total ND & & 1 & 0.02 & 0.03 & $0.32 * *$ \\
Total FD & & & 1 & $0.78^{* * *}$ & $0.72 * * *$ \\
Total AFD & & & & 1 & $0.93 * * *$ \\
Total D & & & & & 1
\end{tabular}

\% PM - Percentage progressive sperm movement; Total ND - Total nuclear defects; Total FD - Total flagellar defects; Total AFD - Total acrosome and flagellar defects; Total D - Total sperm defects (normal-, nuclear-, acrosomal- and flagellar defects); $* * * \mathrm{P}<0.001 ; * * \mathrm{P}<0.05 ; *$ Not significant. 
Table 6 Correlation coefficients between different sperm motility characteristics of 25-month old Bonsmara bulls

\begin{tabular}{|c|c|c|c|}
\hline & $\begin{array}{c}\% \text { Progressive sperm } \\
\text { movement }\end{array}$ & $\begin{array}{c}\% \text { Aberrant sperm } \\
\text { movement }\end{array}$ & $\begin{array}{c}\% \text { Immotile } \\
\text { sperm }\end{array}$ \\
\hline$\% \mathrm{PM}$ & 1 & $-0.96 * * *$ & $-0.94 * * *$ \\
\hline$\% \mathrm{AM}$ & & 1 & $0.83 * * *$ \\
\hline$\%$ I & & & 1 \\
\hline
\end{tabular}

usually involve the coiling or bending of the principle piece and motility is impaired and this causes a negative effect on fertility as the sperm cannot move in a forward direction due to the bending of the tail and is unable to penetrate the zona pelucida (Barth \& Oko, 1989). The occurrence of acrosomal and flagellar defects can also be due to semen collection and the handling or due to lengthy storage in the epididymis before ejaculation (senescent sperm). During the present study the bulls were given the opportunity to service a cow and thus ejaculate (during the libido test) prior to semen evaluation. Similarly, semen collection was carried out at a warm ambient temperature, taking care to protect the ejaculate from UV light and temperature fluctuations. It can therefore be assumed that the acrosomal defects were not artefactual.

Many inconsistencies exist between libido tests that make the interpretation of results very difficult (Petheric, 2004). When differentiating between bulls of high, medium or low libido, the bulls must be given the opportunity to express their maximum libido (Blockey, 1981a) and there are many precautions to be taken when testing bulls for libido and mating ability (Chenoweth, 1999). The bulls should not be tested during periods of adverse weather conditions such as extreme heat, cold or wind (Chenoweth, 1999). Extremes in thermal environments and climates can reduce the expression of libido (Petheric, 2004; Quirino et al., 2004) and must be considered when interpreting libido score results (Landaeta-Hernandez et al., 2001). Existing methods used to determine the sexual behaviour of bulls may also be impeded by the fact that they involve the use of restrained, non-oestrous females that do not represent natural mating stimuli (Quirino et al., 2004; Bailey et al., 2005). It has been shown that a group of unrestrained, sexually receptive females induce greater sexual responsiveness in bulls than sequentially pairing them with individual females. Other practices such as using restrained, non-oestrous females or even restrained male cattle in serving capacity tests seems questionable (Bailey et al., 2005). Testing of bulls immediately following other procedures such as electro-ejaculation, vaccination and parasite control measures should also be avoided (Chenoweth, 1999).

Petherick (2005) emphasized that cattle in groups interact and develop relationships with each other. One form of this relationship is a dominance hierarchy or social order. It has been reported by Lopez et al. (1999) that the sexual behaviour of other males can be inhibited by the presence of a more dominant male. The length of time that the bull has spent in the herd tends to determine the dominance of that bull and this is closely associated with the bull's age. Bulls that have been reared together and are of a similar age are less likely to compete (Ologun et al., 1981) and libido testing should therefore be done in groups of similar ages to reduce the effect of social dominance on the expression of libido (Chenoweth, 1999). Dominance is of little importance when yearling or two year old bulls are used (Petherick, 2005).

Libido score did not influence the potential breeder categories (Table 7). Bulls with $\geq 70 \%$ morphologically normal sperm had a higher overall libido score $(5.3 \pm 1.6)$, compared with bulls with $<70 \%$ morphologically normal sperm $(4.5 \pm 1.6)$. These results indicate that the sperm morphology category may be a more accurate predictor of libido than the sperm motility category.

The results of the present study revealed that bulls that had a SC $\geq 340 \mathrm{~mm}$ at the beginning of the trial tended to have a slightly higher libido score $(4.8 \pm 1.6)$ in comparison with bulls with a SC $<340 \mathrm{~mm}(4.2 \pm$ 1.5), which agrees with the results of Crichton \& Lishman (1984). A study done by Ologun et al. (1981) found contradictory results when comparing the average daily gain and weights of yearling bulls after a 140day performance test, to the libido/serving capacity scores obtained during a libido test where restrained, 
Table 7 The effect of fertility categories on the libido score of 25-month old Bonsmara bulls

\begin{tabular}{lll}
\hline Fertility category & Classification & Libido score \pm s.d. \\
\hline \multirow{2}{*}{ SMPC } & $\geq 70 \%$ & $5.3 \pm 1.6$ \\
& $<70 \%$ & $4.5 \pm 1.6$ \\
\hline SMTC & $\geq 70 \%$ & $4.7 \pm 1.6$ \\
& $<70 \%$ & $4.7 \pm 1.7$ \\
\hline
\end{tabular}

SMPC - Sperm morphology category; SMTC - Sperm motility category.

non-oestrous females were used. It was reported that a negative correlation $(\mathrm{P}<0.01)$ exists between both ADG and final body weight with serving capacity score. The results indicate an unfavourable relationship between production traits and libido. The conflicting results between the present study and that of Ologun et al. (1981) may be explained by the different female stimuli, and thus, different libido testing procedures used during the two studies. The temporal expression of a bull's sexual behaviour has been found to vary with the type of female stimulus used during the testing procedure (Bailey et al., 2005) and some bulls may show temporary deficiencies in libido when females are used that are not in oestrus (Quirino et al., 2004).

Another study performed by Quirino et al. (2004) to assess the relationship between libido and seminal traits of 2- to 5-year old zebu bulls reported a libido score of 2.4 for two-year old bulls, and a negative correlation between libido and scrotal circumference $(\mathrm{r}=-0.2 ; \mathrm{P}<0.05)$, suggesting that the bulls with the highest libido had a smaller SC.

\section{Conclusion}

From the results of this study it can be concluded that production data cannot be used to predict the breeding potential of young bulls. The negative correlations between the 205-day growth index and total acrosomal and flagellar defects, and the positive correlation between 205-day growth index and sperm motility, suggest that high growth rates before weaning may have a positive effect on the breeding potential of a bull. None of the reproductive and production- and growth data had a significant effect on libido scores and would thus not be reliable predictors of libido in young extensively managed bulls.

\section{Acknowledgements}

The authors would like to express their gratitude to A.M. de Villiers Jr. of Vrede, South Africa for supplying the bulls and facilities used during this project.

\section{References}

Bailey, J.D., Anderson, L.H. \& Schillo, K.K., 2005. Effects of sequential or group exposure to unrestrained estrous females on expression of sexual behavior in sexually experienced beef bulls. J. Anim. Sci. 83, 1801-1811.

Barth, A.D. \& Oko, R.J., 1989. Abnormal Morphology of Bovine Spermatozoa. Iowa State University Press, Iowa, USA.

Bearden, H.J., Fuquay, J.W. \& Willard, S.T., 2004. Applied Animal Reproduction. 6th ed. Pearson Prentice Hall. New Jersey, USA.

Blockey, M.A., 1981a. Development of a serving capacity test for beef bulls. Appl. Anim. Ethol. 7, 307-319.

Blockey, M.A., 1981b. Further studies on the serving capacity test for beef bulls. Appl. Anim. Ethol. 7, 337-350.

Bourdon, R.M., 2000. Understanding Animal Breeding, $2^{\text {nd }}$ ed. Prentice-Hall, Upper Saddle River, New Jersey, USA.

Boyd, G.W. \& Corah, L.R., 1988. Effect of sire and sexual experience on serving capacity of yearling beef bulls. Theriogenology 29, 779-790.

Burrow, H.M. \& Prayaga, K.C., 2004. Correlated responses in productive and adaptive traits and temperament following selection for growth and heat resistance in tropical beef cattle. Livest. Prod. Sci. 86, 143-161. 
Chenoweth, P.J., 1986. Libido testing. Theriogenology 26, 136-142.

Chenoweth, P.J., 1999. Assessment and management of breeding bulls. Rev. Fac. Agron. 16, 667-689.

Chenoweth, P.J., Farwin, P.W., Mateos, E.R., Rupp, G.P. \& Pexton, J.E., 1984. Breeding soundness and sex drive by breed and age in beef bulls used for natural mating. Theriogenology 22, 341-349.

Chenoweth, P.J., Farin, P.W. \& Mateos, E.R., 1988. Relationship between breeding soundness and sex drive classification in beef bulls. Theriogenology 30, 227-233.

Crichton, J.S. \& Lishman, A.W., 1985. Libido evaluation of virgin beef bulls. S. Afr. J. Anim. Sci. 15, 22-24.

Crichton, J.S., Lishman, A.W. \& Lesch, S.F., 1987. Failure to demonstrate a relationship between beef bull libido and conception rate. S. Afr. J. Anim. Sci. 17, 27-30.

Ellis, R.W., Rupp, G.P., Chenoweth, P.J., Cundiff, L.V. \& Lunstra, D.D., 2005. Fertility of yearling beef bulls during mating. Theriogenology 64, 657-678.

Farin, P.W., Chenoweth, P.J., Tomky, D.F., Ball, L. \& Pexton, J.E., 1989. Breeding soundness, libido and performance of beef bulls mated to estrous synchronized females. Theriogenology 32, 717-725.

Godfrey, R.W. \& Lunstra, D.D., 1989. Influence of single or multiple sires and serving capacity on mating behavior of beef bulls. J. Anim. Sci. 67, 2897-2903.

Hoflack, G., Van Soom, A., Maes, D., de Kruif, A., Opsomer, G. \& Duchateau, L., 2006. Breeding soundness and libido examination in Belgium Blue and Holstein Friesian Artificial Insemination bulls in Belgium and the Netherlands. Theriogenology 66, 207-216.

Knights, S.A., Baker, R.L., Gianda, D. \& Gibb, J.B., 1984. Estimates of heritabilities and of genetic and phenotypic correlations among growth and reproductive traits in yearling Angus bulls. J. Anim Sci. 58, 887-893.

Landaeta-Hernández, A.J., Chenoweth, P.J. \& Berndtson, W.E., 2001. Assessing sex drive in young Bos taurus bulls. Anim. Reprod. Sci. 66, 151-160.

López, H., Orihuela, A. \& Silva, E., 1999. Effect of the presence of a dominant bull on performance of two age group bulls in libido tests. Appl. Anim. Behav. Sci. 65, 13-20.

Lunstra, D.D. \& Coulter, G.H., 1997. Relationship between scrotal infrared temperature patterns and natural mating fertility in beef bulls. J. Anim. Sci. 75, 767-774.

Lunstra, D.D., Ford, J.J. \& Echternkamp, S.E., 1978. Puberty in beef bulls: Hormone concentrations, growth, testicular development, sperm production and sexual aggressiveness in bulls of different breeds. J. Anim. Sci. 16, 1054-1062.

Lunstra, D.D., Boyd, G.W. \& Corah, L.R., 1989. Effects of natural mating stimuli on serum Luteinizing hormone, testosterone and estradiol-17 $\beta$ in yeafling beer bulls. J. Anim. Sci. 67, 3277-3288.

Moser, D.W., Bertrand, J.K., Benyshek, L.L., McCann, M.A. \& Kiser, R.E., 1996. Effects of selection for scrotal circumference in Limousin bulls on reproductive and growth traits of progeny. J. Anim. Sci. 74, 2052-2057.

Ologun, A.G., Chenoweth, P.J. \& Brinks, J.S., 1981. Relationships among production traits and estimates of sex drive and dominance values in yearling beef bulls. Theriogenology 15, 379-388.

Palmer, C.W., Brito, L.F.C., Arteaga, A.A., Soderquist, L., Persson, Y. \& Barht, A.D., 2005. Comparison of electroejaculation and transrectal massage for spermatozoal collection in range and yearling feedlot beef bulls. Anim. Reprod. Sci. 87, 25-31.

Parkinson, T.J., 2004. Evaluation of fertility and infertility in natural service bulls. Vet. J. 168, 215-229.

Petherick, J.C., 2005. A review of some factors affecting the expression of libido in beef cattle, and individual bull and herd fertility. Appl. Anim. Behav. Sci. 90, 185-205.

Quirino, C.R., Bergmann, J.A.G., Vale Filho, V.R., Andrade, V.J., Reis, S.R., Mendonca, R.M. \& Fonseca, C.G., 2004., Genetic parameters of libido in Nellore bulls. Theriogenology 62, 1-7.

SAS, 2004. SAS Procedures Guide, Version 9.1. SAS Institute Inc., Cary, N.C., USA.

Smith, M.F., Morris, D.L., Amoss, M.S., Parish, N.R., Williams, J.D. \& Wiltbank, J.N., 1981. Relationships among fertility, SC, seminal quality, and libido in Santa Gertrudis bulls. Theriogenology 16, 379-397.

Vilakazi, D.M. \& Webb, E.C., 2004. Effect of age and season on sperm morphology of Friesland bulls at an artificial insemination centre in South Africa. S. Afr. J. Anim. Sci. 34, 62-69. 